\title{
An experimental test of Jameson and Hurvich's theory of brightness contrast ${ }^{1}$
}

HOWARD R. FLOCK ${ }^{2}$ YORK UNIVERSITY, AND KAORU NOGUCHI, CHIBA UNIVERSITY, JAPAN

Two hundred and fifty-two brightness functions for seven simultaneously presented black, gray, and white squares on black, gray, and white backgrounds approximated power curves with positive exponents when illuminance was varied in seven steps over $1.9 \mathrm{log} f L$. Mean exponents were significantly larger for whiter vs blacker squares and for squares on the white vs the gray background. Mean exponents also increased more for squares on white than on black or gray backgrounds. Finally, a white replacing a black background elicited increasingly larger decremental responses as the squares varied from black to white. Jameson and Hurvich's opponent-process theory, tested by the experiment, was not predictive.

Several theories attempt to explain why black, gray, and white surfaces continue to appear black, gray, and white despite changing illumination. This problem is known under the term of brightness constancy and has been described by many writers (e.g., Helson, 1943, 1968; Jameson \& Hurvich, 1961; Wallach 1948; Woodworth \& Schlosberg, 1954). Recently, Jameson and Hurvich (1961) disputed the theories of Helson (1943), Wallach (1948) and Woodworth and Schlosberg (1954) as they applied to the empirical data on brightness constancy. By implication their arguments also were against the older explanations from which these theories were derived [Gelb (1929) and Koffka (1935) in the case of Helson and Wallach; and Helmholtz (1925) and Katz (1935) in the case of Woodworth and Schlosberg]. In place of these theories Jameson and Hurvich (1964) proposed a model that is consistent with opponent process theory. (For a review of this model, see Flock, 1970.)

Jameson and Hurvich (1961) primarily objected to the older theories because of their inability to explain the data from Jameson and Hurvich (1961). The cited data do offer problems to the older theories. The problem of these data for theory is manifest in a graphic representation (Flock, 1970, Fig. 2) of Jameson and Hurvich's (1961) data.

In that log-log plot Jameson and Hurvich's (1961) brightness functions were shown by Flock as power curves. The brightness functions were plotted against focal luminance with contrast ratio ( $C R$, ratio of surround to focal luminance) constant for each function. There were five linear functions on the plot, each representing a different $C R$. Since $C R$ was constant for each function, focal luminance on the abscissa indicated illuminance in arbitrary units.

The major problem for the older theories was the finding that the five lines had different signs. Three of the lines were pronouncedly positive with mean slopes (bs) of .24, .21, and .34; one was almost flat with $\bar{b}=.06 ;$ and one was pronouncedly negative with $\bar{b}=-.66$. The positive lines corresponded to focal regions that would objectively be called white, light gray, mid-gray, respectively, and had relatively small CRs; the negative line to a region that would objectively be called black and had a relatively large CR; and the intermediate line to a region that would be called middle gray or dark gray and had a relatively intermediate $C R$. In other words, as argued by Jameson and Hurvich (1961, p. 175), when illuminance was varied over $1.1 \log$ units in three steps, the lightest regions became lighter; the darkest region became darker; and the intermediate region didn't change. The older theories would have difficulties, it was argued, explaining these different signs.

Flock (1970) has shown that Jameson and Hurvich's (1964) model could yield outputs with some similarities to Jameson and Hurvich's (1961) data. For one thing, under the appropriate conditions the model would generate power curves with positive exponents for relatively small CRs, negative exponents for relatively large CRs, and one zero exponent for an intermediate $\mathrm{CR}$, which is approximately what was found in Jameson and Hurvich's (1961) data.

To be more precise, according to the model all of the positive and negative exponents must be $|.33|$. Whether the exponents ( $\bar{b}$ cited above) found in Jameson and Hurvich's (1961) data fit those requirements cannot be determined from their report. Since the quintessence of the model lies in this requirement of power curves and exponents with values restricted to $.33,-.33$, and 0 , the test of these requirements will be the primary intent of the experiment described below.

There is a second problem in showing a fit of the data to the model. In order to predict whether exponents should be " + ," " - ," or " 0 " would require the evaluation of an induction coefficient called k. Flock (1970) has raised some doubt as to the feasibility of evaluating $k$, at least under the terms of reference given by Jameson and Hurvich (1964). Without an evaluation of $\mathrm{k}$ it would be impossible to predict from the experimental conditions or even after the fact from the empirical data what the sign of an exponent should be. Hence it is not certain that the model would have predicted the flat and the negative function to be found in Jameson and Hurvich's (1961) data under their experimental conditions.

Because the model as presently defined will not predict what signs should occur in an experiment, its predictive power is limited. Nevertheless, if the "-" function observed in Jameson and Hurvich's data is a reliable and appropriate fluctuation under the model for their experimental conditions, then perhaps there is a way of increasing the probability of observing "-" functions. According to the model a "-" function will occur when CR is sufficiently large, when the separation between the surround and the focal region is sufficiently small, and when the ratio of surround to focal area is sufficiently large. Starting with the experimental conditions under which Jameson and Hurvich observed a "_." function, one would simply increase $C R$, decrease separation between surround and focal region, and decrease the angular size of the focal region. These changes in their arrangements should enhance the possibility of observing "-." functions. And so these changes were introduced into the experiment described below.

The observation of "-" functions is being emphasized here because their occurrence is what, according to Jameson and Hurvich (1961), most embarrassed the older theories.

The generality of Jameson and Hurvich's "_" function should also be of some interest. It was defined by three mean data points, only one of which had a pronounced negative fluctuation. That single point was the mean of a pair of observations by three observers. In the experiment described below, therefore, the number of points defining a curve, the range of the illuminance, and the sample size were increased. In a number of other ways, 
also, the experimental arrangements departed from those used by Jameson and Hurvich (1961). Those departures and the reasons for them will be described and discussed later.

\section{METHOD}

\section{Subjects}

Twelve $S$ s participated in the experiment. Their median age was 20 , they were naive to the purposes of the experiment, and all $S_{s}$ had uncorrected $20 / 20$ vision in each eye.

\section{Apparatus}

A cross-shaped configuration composed of seven Munsell neutral $(N)$ grays was mounted on a Munsell $\mathrm{N}$ gray background. It was mounted frontally at an optical distance of $230 \mathrm{~cm}$ and was viewed under constant Illumination by the left eye through a circular aperture. Under these conditions the background luminance was $1.64 \log \mathrm{fL}$. The five grays in the vertical shaft of the cross from top to bottom gave luminances of $1.79,1.58,1.95, .70$, and $.15 \log \mathrm{fL}$. The luminances of the two grays to the left and right of the center gray were 1.19 and $1.67 \log \mathrm{fL}$. The difference between the lightest and darkest region was $1.80 \log \mathrm{fl}$. Each patch of gray, measuring $3 \mathrm{~cm}$ on a side, subtended approximately $45 \mathrm{~min}$ of arc and the total angular diameter of the display, including the configuration and the background, was $5 \mathrm{deg}$. The configuration is shown schematically in Fig. 1.

A Leitz Prado 500 projector with a Sylvania 500-W lamp and a lens with a focal length of $100 \mathrm{~mm}$ illuminated the display. It was suitably screened to reduce stray light. A neutral density filter with a density of 1.0, manufactured by Optics Technology, was placed in front of the lens. The optical path from the left eye included a right-angle prism, two diaphragms, and a front-surfaced mirror, as shown in Fig. 2. The diaphragm adjacent to the prism had an opening of $20 \mathrm{~mm}$. This left eye field or reference field will be referred to as the modulus field (MF).

An identical arrangement was constructed for the right eye with the following additions: Interposed in the optical path of the right eye was a solenoid-operated shutter that introduced a round homogeneous adaptation field $5 \mathrm{deg}$ in diam to the right eye between each trial. The luminance of the adaptation field throughout the experiment was $1.64 \log \mathrm{fL}$, the same as that of the gray background in the MF. By introducing neutral density filters (with densities of $2.0,1.72,1.37,1.0, .72, .37$, and 0 ) in front of the lens of the projector in the right eye field, the illumination of the right

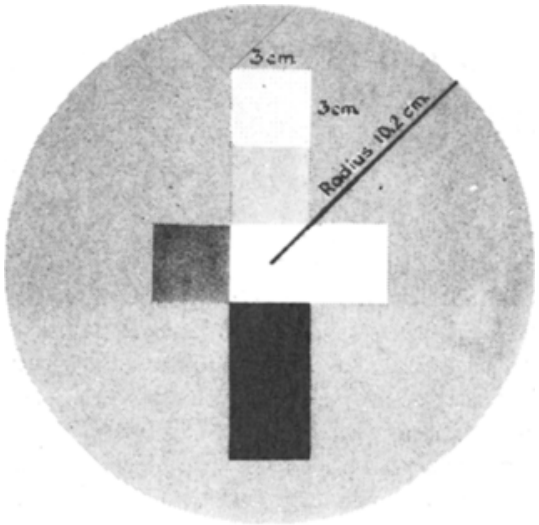

Fig. 1. Representation of the relative luminences of the seren test-field squares on the gray backeround.

eye could be varied over seven approximately equal $\log$ steps. These $\log$ steps as measured with a Pritchard Spectraphotometer and expressed as log luminances (fL) of the white (and brightest) square in the center of the cross were: $.97,1.30,1.61,1.95,2.18,2.52$, and 2.88. The range of iluminance was, therefore, $1.91 \log \mathrm{fL}$.

In addition to the configuration of gray patches on a gray background, identical displays were made with Munsen papers from the same dye batches but with white and black backgrounds. The huminances (in $\log (\mathrm{f})$ of the seven grays on a black, gray, and $a$ white background for the seven Tllumination levets can be found in Table 2; and the huminances of the backgrounds ${ }^{3}$ are given at the heads of the columns.

These three displays were held in a frontal position in the right eye field by attaching shim metal to their backs and using magnetic strips on a fixed surface. This procedure also allowed rapid interchange of the displays. The right eye field is referred to below as the test field (TF), the individual patches of gray in the cross as the TF squares, and the backgrounds of the TF squares as the TF background.

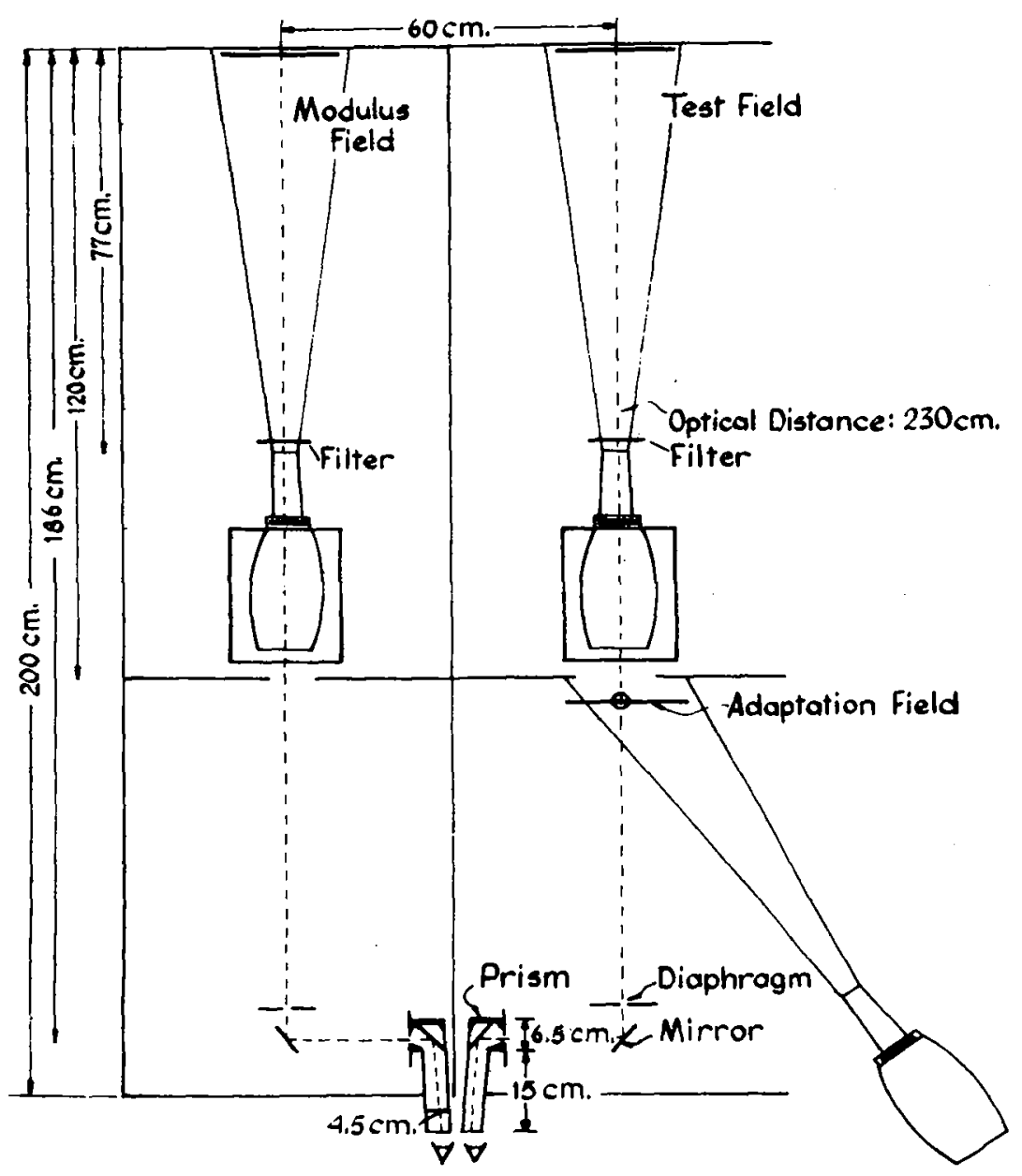

Fig. 2. Schematic drawing of the apparatus. 
Although these arrangements of the apparatus produced a dichoptic viewing situation, the apparatus was arranged so that the MF squares and the TF squares could not be imaged in the fovea simultaneously. When, for example, the MF illuminated the fovea of the left eye, the TF was displaced into the periphery of the right eye. These arrangements precluded peripheral but not central interactions between the two fields. A chin rest and head rest could be adjusted to keep the S's eyes at the level of the eyepiece. And each eyepiece was individually adjustable.

\section{Procedure}

On each trial $S$ was asked to look at a particular square in the MF configuration, to let its brightness equal 100 , and then to indicate the apparent brightness of the corresponding square in the TF by assigning a number to it. (The corresponding TF square was identified by its location.) The $S$ was allowed to look back and forth from MF to TF. Although Jameson and Hurvich's (1961) procedures apparently made no distinction between apparent brightness and blackness or whiteness, the instructions to the Ss emphasized brightness rather than whiteness, grayness, or blackness. This emphasis occurred during the initial instructions, during the period of dark-adaptation, during the practice trials, and before the first experimental trial. The instruction before his initial judgment was: Remember, you are to assign numbers proportional to your impression of the brightness, not of the whiteness, grayness, or blackness of the squares.

The $S$ s were given practice in making magnitude estimates and were given examples like the following: Keep in mind that each of the squares in the configuration in the left eye is always assigned the number 100 . If a corresponding square on the right appeared two times as bright, what number would you assign to it? If it appeared one-half as bright? One-fourth as bright?

At the start of the experiment the $S$ was dark adapted for $10 \mathrm{~min}$. A $S$ was then tested over the seven TF squares on some background at either the lowest or the highest of the seven illumination levels. At the end of the block of seven trials, which were presented in random order with a 5 -sec adaptation field between trials, $S$ was dark adapted for $60 \mathrm{sec}$ in both eyes while the illumination level was changed in either an ascending or descending order. Continuing in this manner the $\mathrm{S}$ was tested over all seven squares on a particular background for all seven illumination levels. Background was then changed while the $\mathrm{S}$ was dark adapted for $5 \mathrm{~min}$ in both eyes. The same procedure (with the same order of presentation of illumination levels) was then repeated for a different background. The order in which the backgrounds were given was counterbalanced over the Ss. Finally, the experiment was replicated on the $S$ after a 15-min rest period. During the replication the order of presentation of the illumination levels was reversed from the first part of the experiment.

The design of the experiment required each $S$ to make 294 judgments: seven ilumination levels $x$ three background levels $x$ seven $T F$ squares $x$ two replications. Each judgment was transformed to a $\log$ magnitude estimate and the two replications for each condition were averaged. For each $S$, therefore, there were 21 curves. Each curve described the fluctuation of the log magnitude estimates over seven levels of illuminance for a TF square on a background.

\section{RESULTS AND DISCUSSION}

\section{(1) The Functions as Power Curves}

If the 21 curves for each $S$ were power curves, then for the $\log -\log$ relationship (log magnitude estimate of brightness and log illuminance) the curves would be straight lines. The degree of scatter of an S's seven mean data points around these straight lines would be indexed by $r^{2}$, where $r^{2}$ describes the proportion of the total judgmental fluctuation over illuminance that is linear. Table $1 \mathrm{~A}$ gives a frequency distribution of $r^{2}$ (as a percentage) for the total of 252 curves (seven TF squares $x$ three backgrounds $x$ $12 \mathrm{Ss}$ ).

For Rows 1 and 2 of Table $1 \mathrm{~A} 80 \%$ to $100 \%$ of a total fluctuation was linear variance. In those rows are to be found 194 or $77 \%$ of the total number of curves. Hence, for $77 \%$ of the curves, $80 \%$ or more of the individual variance was linear variance. The degree to which the data were linear will be appreciated if it is remembered that as the slope of a straight line approaches zero, $\mathbf{r}^{2}$ is forced also toward zero, provided that the scatter of points around the line is independent but finite. It will be seen shortly that many of these lines had slopes close to zero. Nevertheless, despite this constraint, $\mathrm{r}^{2}$ remained at or above $80 \%$ for $77 \%$ of the curves (and at or above $70 \%$ for $85 \%$ of the curves). The assumption that the true curves are power curves seems, therefore, to be at least tenable.

\section{(2) The Signs of the Exponents}

Treated as power curves the fluctuations of log magnitude estimates over the seven levels of $\log$ illuminance were fitted by best-fit least-squares straight lines. The slopes (linear regression coefficients bs) of these lines are the exponents of the power curves. (In the discussion below, therefore, the terms exponents and slopes will be used interchangeably.) Table $1 \mathrm{~B}$ gives a frequency distribution of the 252 bs for the seven TF squares $x$ three backgrounds $\mathrm{x} 12 \mathrm{Ss}$.

No negative exponents were observed

Table 1

Measures of Individual $(\mathbf{N}=12)$ Variability for Three Backgrounds and Seven Squares

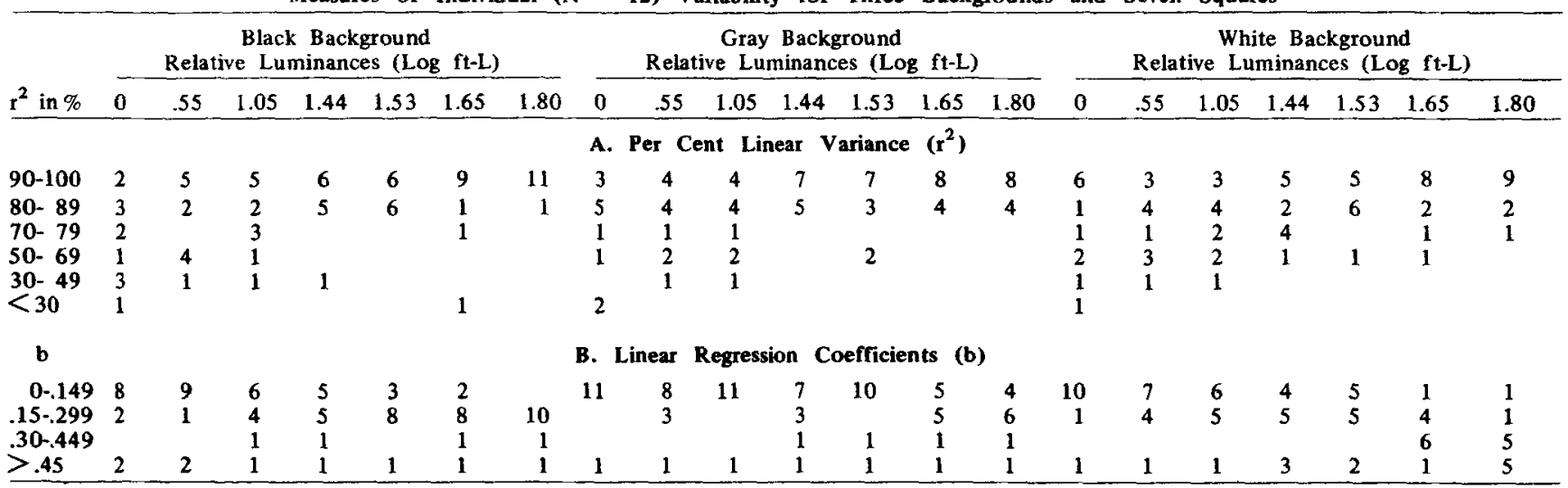


for any $S$ at any treatment level. Even when the black TF square was judged against a white background, no negative exponents occurred (Column 1 under white background). It will be recalled that in this experiment attempts were made to maximize the probability of observing negative coefficients. To accomplish this, a number of changes were made: First, the TF squares were made angularly smaller than the ones used by Jameson and Hurvich (1961). As a result, the ratio of the angular width of a square to the angular width of the display was reduced from the value of .27 (3-deg width of a TF square/11-deg width of display) used by Jameson and Hurvich to .15 (0.75-deg width of TF square/5-deg width of display) in this experiment.

Second, the CRs were increased between the darkest TF squares and their backgrounds. Jameson and Hurvich's (1961, Fig. 1) cross had five squares: white in the center, black below, dark gray to the left, light gray to the right, and mid-gray above. The cross was placed on a mid-gray background. As a result, Jameson and Hurvich's darkest (black) square was surrounded on three sides by a background that may have been approximately 1.I $\log \mathrm{mL}$ greater in luminance. On the fourth side, it was bounded by the white square that was $1.43 \log \mathrm{mL}$ greater in luminance. Two of the remaining TF squares touched corners with the black square and may have contributed to the brightness of the black square, either by direct inhibition or by disinhibition. The $\log C R$ for the black square and its complex background was, presumably, between 1.1 and 1.43 , and was probably closer to 1.1 .

In the present experiment both the black and dark gray TF squares on a white background were surrounded on three sides by white (Fig. 1). The difference between the black square and the white background was $1.90 \log \mathrm{fL}$ (see Table 2) and between the dark gray square and the white background, $1.35 \log \mathrm{fL}$. Although the fourth side of these two squares was bounded by a dark square, both squares on that side were only $45 \mathrm{~min}$ of arc removed from a white region (again see Fig. 1). Hence it would seem reasonable to assume that CR was larger for both of these squares on a white background than it was for Jameson and Hurvich's black square. Moreover, CR for the black square on the mid-gray background in this experiment was also, perhaps, greater than the CR used by Jameson and Hurvich.

Third, the black square in the present experiment was more fully surrounded by the white background than was the case for Jameson and Hurvich's black square on a gray background. In that sense the black square was more removed from lower-luminance and was more adjacent to higher-luminance surrounds than was the case earlier. This was accomplished by stretching the vertical shaft of the cross to five squares from the three used earlier and by placing the black square at the bottom of the shaft. In this way the wings of the cross would have less effect on the black square and would be less likely to inhibit the white surround adjacent to the black square.

In addition to these efforts to obtain negative functions, two other changes were made, which, it was hoped, would yield negative functions. First, if negative functions were not general to all Ss but were specific to some, then by increasing the sample size from the three Ss used by Jameson and Hurvich to 12, the probability of failing to catch at least one such $S$ in the randomly chosen sample, even assuming him to be as rare as one in four in the population, would be less than .05 .

Second, by increasing the range of illuminance from 1.1 to $1.91 \log$ units and the number of illumirance steps from three to seven, any occurrence of negative functions would have that much more generality and reliability.

Despite all of these changes, engineered to maximize the probability of observing negative functions, none were observed. Since the occurrence of negative functions is crucial to the credibility of Jameson and Hurvich's (1964) model and to the dismissal of the older theories, the failure

Table 2

Mean Log Magnitude Estimates for Seven Gray Squares on Three Backgrounds Over Seven Levels of Illumination for Twelve Subjects. Luminances of Squares and Backgrounds in $\log \mathrm{fL}$.

Illumination Levels

\begin{tabular}{|c|c|c|c|c|c|c|c|c|c|c|c|c|c|c|c|c|}
\hline \multirow[b]{3}{*}{$\begin{array}{c}\text { Gray } \\
\text { Squares }\end{array}$} & \multicolumn{4}{|c|}{ Dim } & \multicolumn{4}{|c|}{ Low } & \multicolumn{4}{|c|}{ Below Modulus } & \multicolumn{4}{|c|}{ Equal to Modulus } \\
\hline & \multirow[b]{2}{*}{$\begin{array}{c}\text { Lumin- } \\
\text { ances }\end{array}$} & \multicolumn{3}{|c|}{ Background } & \multirow[b]{2}{*}{$\begin{array}{c}\text { Lumin- } \\
\text { ances }\end{array}$} & \multicolumn{3}{|c|}{ Background } & \multirow[b]{2}{*}{$\begin{array}{c}\text { Lumin- } \\
\text { ances }\end{array}$} & \multicolumn{3}{|c|}{ Background } & \multirow[b]{2}{*}{$\begin{array}{c}\text { Lumin- } \\
\text { ances }\end{array}$} & \multicolumn{3}{|c|}{ Background } \\
\hline & & $\begin{array}{c}\text { Black } \\
-.29 \\
\end{array}$ & $\begin{array}{c}\text { Gray } \\
.67 \\
\end{array}$ & $\begin{array}{c}\text { White } \\
1.08 \\
\end{array}$ & & $\begin{array}{c}\text { Black } \\
.04 \\
\end{array}$ & $\begin{array}{c}\text { Gray } \\
.99 \\
\end{array}$ & $\begin{array}{c}\text { White } \\
1.38 \\
\end{array}$ & & $\begin{array}{c}\text { Black } \\
.34 \\
\end{array}$ & $\begin{array}{l}\text { Gray } \\
1.32 \\
\end{array}$ & $\begin{array}{c}\text { White } \\
1.71 \\
\end{array}$ & & $\begin{array}{c}\text { Black } \\
.68 \\
\end{array}$ & $\begin{array}{l}\text { Gray } \\
1.64 \\
\end{array}$ & $\begin{array}{c}\text { White } \\
2.04\end{array}$ \\
\hline $\begin{array}{l}1 \\
2\end{array}$ & $\begin{array}{l}-.82 \\
-.27\end{array}$ & $\begin{array}{l}1.77 \\
1.81\end{array}$ & $\begin{array}{l}1.92 \\
1.86\end{array}$ & $\begin{array}{l}1.88 \\
1.78\end{array}$ & $\begin{array}{r}-.51 \\
.04\end{array}$ & $\begin{array}{l}1.83 \\
1.91\end{array}$ & $\begin{array}{l}1.95 \\
1.91\end{array}$ & $\begin{array}{l}1.88 \\
1.88\end{array}$ & $\begin{array}{r}-.19 \\
.36\end{array}$ & $\begin{array}{l}1.89 \\
1.96\end{array}$ & $\begin{array}{l}1.97 \\
1.94\end{array}$ & $\begin{array}{l}1.96 \\
1.89\end{array}$ & $\begin{array}{l}.15 \\
.70\end{array}$ & $\begin{array}{l}1.94 \\
2.01\end{array}$ & $\begin{array}{l}1.99 \\
1.99\end{array}$ & $\begin{array}{l}2.02 \\
2.00\end{array}$ \\
\hline $\begin{array}{l}3 \\
4 \\
5\end{array}$ & $\begin{array}{l}.23 \\
.61 \\
.70\end{array}$ & $\begin{array}{l}1.87 \\
1.82 \\
1.84\end{array}$ & $\begin{array}{l}1.87 \\
1.81 \\
1.84\end{array}$ & $\begin{array}{l}1.79 \\
1.67 \\
1.71\end{array}$ & $\begin{array}{r}.53 \\
.92 \\
1.00\end{array}$ & $\begin{array}{l}1.90 \\
1.88 \\
1.93\end{array}$ & $\begin{array}{l}1.93 \\
1.86 \\
1.88\end{array}$ & $\begin{array}{l}1.82 \\
1.68 \\
1.71\end{array}$ & $\begin{array}{r}.86 \\
1.26 \\
1.34\end{array}$ & $\begin{array}{l}1.97 \\
1.92 \\
2.00\end{array}$ & $\begin{array}{l}1.95 \\
1.92 \\
1.93\end{array}$ & $\begin{array}{l}1.88 \\
1.80 \\
1.79\end{array}$ & $\begin{array}{l}1.19 \\
1.58 \\
1.67\end{array}$ & $\begin{array}{l}2.05 \\
2.03 \\
2.04\end{array}$ & $\begin{array}{l}1.98 \\
1.99 \\
2.00\end{array}$ & $\begin{array}{l}1.97 \\
1.93 \\
1.94\end{array}$ \\
\hline $\begin{array}{l}6 \\
7\end{array}$ & $\begin{array}{l}.82 \\
.97\end{array}$ & $\begin{array}{l}1.80 \\
1.78 \\
\end{array}$ & $\begin{array}{l}1.77 \\
1.77\end{array}$ & $\begin{array}{l}1.43 \\
1.58\end{array}$ & $\begin{array}{l}1.15 \\
1.30\end{array}$ & $\begin{array}{l}1.90 \\
1.86\end{array}$ & $\begin{array}{l}1.83 \\
1.84\end{array}$ & $\begin{array}{l}1.47 \\
1.59\end{array}$ & $\begin{array}{l}1.46 \\
1.61\end{array}$ & $\begin{array}{l}2.00 \\
1.94\end{array}$ & $\begin{array}{l}1.91 \\
1.91\end{array}$ & $\begin{array}{l}1.51 \\
1.68\end{array}$ & $\begin{array}{l}1.79 \\
1.95 \\
\end{array}$ & $\begin{array}{l}2.07 \\
2.06\end{array}$ & $\begin{array}{l}1.99 \\
1.99 \\
\end{array}$ & $\begin{array}{l}1.93 \\
1.83\end{array}$ \\
\hline
\end{tabular}

\begin{tabular}{|c|c|c|c|c|c|c|c|c|c|c|c|c|}
\hline \multirow[b]{4}{*}{$\begin{array}{c}\text { Gray } \\
\text { Squares }\end{array}$} & \multicolumn{12}{|c|}{ Illumination Levels } \\
\hline & \multirow[b]{3}{*}{$\begin{array}{c}\text { Lumin- } \\
\text { ances }\end{array}$} & \multicolumn{3}{|c|}{ Above Modulus } & \multicolumn{4}{|c|}{ Bright } & \multicolumn{4}{|c|}{ Very Bright } \\
\hline & & \multicolumn{3}{|c|}{ Background } & \multirow[b]{2}{*}{$\begin{array}{l}\text { Lumin- } \\
\text { ances }\end{array}$} & \multicolumn{3}{|c|}{ Background } & \multirow[b]{2}{*}{$\begin{array}{c}\text { Lumin- } \\
\text { ances }\end{array}$} & \multicolumn{3}{|c|}{ Background } \\
\hline & & $\begin{array}{c}\text { Black } \\
.92 \\
\end{array}$ & $\begin{array}{l}\text { Gray } \\
1.88\end{array}$ & $\begin{array}{c}\text { White } \\
2.28\end{array}$ & & $\begin{array}{c}\text { Black } \\
1.26 \\
\end{array}$ & $\begin{array}{r}\text { Gray } \\
2.22 \\
\end{array}$ & $\begin{array}{c}\text { White } \\
2.62 \\
\end{array}$ & & $\begin{array}{c}\text { Black } \\
1.61 \\
\end{array}$ & $\begin{array}{r}\text { Gray } \\
2.58 \\
\end{array}$ & $\begin{array}{c}\text { White } \\
2.98 \\
\end{array}$ \\
\hline 1 氖 & $\begin{array}{l}.38 \\
.93\end{array}$ & $\begin{array}{l}1.99 \\
2.08\end{array}$ & $\begin{array}{l}2.06 \\
2.06\end{array}$ & $\begin{array}{l}2.08 \\
2.08\end{array}$ & $\begin{array}{r}.72 \\
1.28\end{array}$ & $\begin{array}{l}2.10 \\
2.15\end{array}$ & $\begin{array}{l}2.04 \\
2.05\end{array}$ & $\begin{array}{l}2.11 \\
2.09\end{array}$ & $\begin{array}{l}1.08 \\
1.63\end{array}$ & $\begin{array}{l}2.11 \\
2.18\end{array}$ & $\begin{array}{l}2.13 \\
2.13\end{array}$ & $\begin{array}{l}2.16 \\
2.14\end{array}$ \\
\hline $\begin{array}{l}3 \\
4 \\
5\end{array}$ & $\begin{array}{l}1.43 \\
1.81 \\
1.91\end{array}$ & $\begin{array}{l}2.17 \\
2.13 \\
2.15\end{array}$ & $\begin{array}{l}2.06 \\
2.06 \\
2.09\end{array}$ & $\begin{array}{l}2.09 \\
2.03 \\
2.03\end{array}$ & $\begin{array}{l}1.76 \\
2.15 \\
2.25\end{array}$ & $\begin{array}{l}2.19 \\
2.19 \\
2.21\end{array}$ & $\begin{array}{l}2.04 \\
2.05 \\
2.07\end{array}$ & $\begin{array}{l}2.09 \\
2.12 \\
2.08\end{array}$ & $\begin{array}{l}2.12 \\
2.51 \\
2.61\end{array}$ & $\begin{array}{l}2.23 \\
2.24 \\
2.27\end{array}$ & $\begin{array}{l}2.13 \\
2.17 \\
2.19\end{array}$ & $\begin{array}{l}2.16 \\
2.16 \\
2.15\end{array}$ \\
\hline $\begin{array}{l}6 \\
7 \quad \Xi\end{array}$ & $\begin{array}{l}2.03 \\
2.18 \\
\end{array}$ & $\begin{array}{l}2.21 \\
2.15 \\
\end{array}$ & $\begin{array}{l}2.08 \\
2.08 \\
\end{array}$ & $\begin{array}{l}2.11 \\
1.99 \\
\end{array}$ & $\begin{array}{l}2.37 \\
2.52 \\
\end{array}$ & $\begin{array}{l}2.27 \\
2.25 \\
\end{array}$ & $\begin{array}{l}2.09 \\
2.09 \\
\end{array}$ & $\begin{array}{l}2.22 \\
2.14 \\
\end{array}$ & $\begin{array}{l}2.73 \\
2.88 \\
\end{array}$ & $\begin{array}{l}2.34 \\
2.34 \\
\end{array}$ & $\begin{array}{l}2.27 \\
2.26 \\
\end{array}$ & $\begin{array}{l}2.33 \\
2.25 \\
\end{array}$ \\
\hline
\end{tabular}


to find them must reflect on this matter. (3.) The Magnitudes of the Positive Exponents

In the absence of negative functions, the exponents according to the model would be expected to fall into two discrete classes, those centered on an exponent of zero and those centered on an exponent of +.33. In Table 1B, 203 of the $252 \mathrm{bs,}$ or $80 \%$, lie below .30 . If these bs have any reliability, then it should be selfevident that they are not centered on +.33 . Moreover, in the absence of negative bs, it is also the case that the bs in Table 1B are not centered on a value of 0.[The assumption that the numerical usages of the Ss validly specify the amount of change in their brightness experiences may be rejected. Nevertheless, it seems reasonable to accept the numbers as indicating order. If their use only indicates order, then the evidence for concluding that the true brightness functions are power curves and are not centered on +.33 is inadequate. The evidence that the brightness functions are not negative and are not centered on zero is, however, adequate. Since the matter of negative functions is what is crucial to the credibility of Jameson and Hurvich's (1964) model, this aside has no relevance to that question.]

(4) The Mean Exponents and Brightness Constancy

Because there seems to be no support in these data for the quintessence of Jameson and Hurvich's (1964) model, little will be served by further laboring the matter. Rather, it will be more useful to examine the data for what they indicate about brightness constancy and brightness functions under conditions of simultaneous brightness contrast.

Table 2 gives the mean log magnitude estimates for each of the seven levels of illumination, seven TF squares, and three backgrounds; and Table 3 gives the mean linear regression coefficients (bs) for each of the TF squares under each of the background conditions. The $21 \overrightarrow{b s}$ in Table 3 vary from .10 to .54 . (The standard error of the mean coefficients, derived from the Background $\times$ TFs $\times$ Ss' residual mean square of .0055 with $132 \mathrm{df}$, was .0215.) Since the lowest mean coefficient, $\bar{b}=.10$, was more than four standard-error deviations from the theoretical value of $\vec{b}=0$, it would be reasonable to assume that all of the mean coefficients were significantly different from $\bar{b}=0$. (Using the same standard error one could test how many observed $\bar{b}$ s fall within specified confidence limits around $\bar{b}=+.33$.) On these grounds perfect brightness constancy, as would be specified by $\bar{b}=0$, did not occur under these experimental conditions.
Not only was brightness constancy not perfect, but it systematically became less perfect as the TF squares were varied from black to white. This significant main effect $(F=25.7, \quad$ df $=6 / 66, \quad p<.01)$ occurred also at each background level. This can be seen within each row of $\bar{b}$ in Table 3. There tends to be a clear positive correlation between luminance (and therefore lightness) of the TF squares and the regression coefficients.

Background also had a significant main effect on the amount of brightness constancy observed $(F=13.2$, df $=2 / 22$, $\mathrm{P}<.01)$. Examination of the $\overrightarrow{b s}$ in each row of Table 3 indicates them to be relatively small in magnitude for the gray background, relatively large for the white background, and intermediate for the black background. The grand mean (GM) for each row is given in the last column of the table. Moreover, except for a reversal in the first column of the table, where $\bar{b}(=.16)$ for the white background is smaller than $\bar{b}$ $(=.19)$ for the black background, this main effect held for each column of the table. Thus, background had nearly constant effects on brightness functions for each TF square. A gray background flattened them; a white background steepened them; and a black background fell in between in its effects.

Background had one other significant effect. The range of the $\overrightarrow{b s}$ for the black background was .11 (from .19 to .30); for the gray background it was .14 (from .10 to .24); but for the white background it was .38 (from .16 to .54). The effect of background on the range of the $\bar{b}$ s was significant $(F=5.7, \mathrm{df}=12,32, \mathrm{P}<.01)$. It should be noted, however, that the major contribution to the interaction came from the two white TF squares with $\bar{b} s$ of .54 and .39. Except for them, the ranges and the shapes of the fluctuations from row to row were rather similar.

In summary, the picture of brightness

Table 3

Mean Linear Coefficients ( $\bar{b})$, Two Measures of $y$-Intercepts $\left(\overline{\mathbf{Y}}\right.$ and $\overline{\mathbf{Y}}_{\mathrm{m}}$ ), and Grand Means for 12 Ss

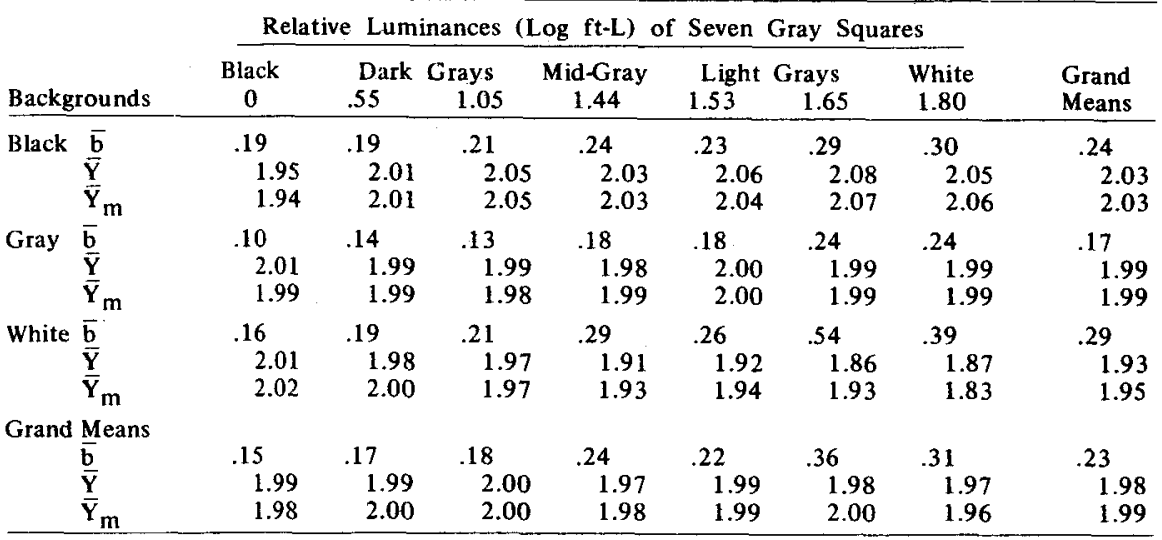

constancy from these results seems to be this: (1) Brightness constancy is not perfect. Its degree of imperfection, given by the departure of $\bar{b}$ from zero, varies from .10 to .54 . (2) On the average, with reference to the black background, less brightness constancy occurs with a white and more with a gray background. This average effect tends to occur at all but one of the levels of TF squares. (3) On the average, black TF squares yield more and white TF squares less constancy than do gray TF squares, regardless of background. (4) But a white background produces the largest decreases in brightness constancy as TF squares are varied from black to white.

\section{(5) The $y$-Intercepts and Simultaneous} Brightness Contrast

lo complete the general picture of these data, consideration must be given to the location ( $y$-intercept) of the brightness functions in the space defined by $\log$ brightness and log illuminance. Two procedures are available for calculating the $y$-intercepts.

First, a y-intercept could be calculated as the mean of the $\log$ magnitude estimates for the seven illuminances at some level of background and TF square. These are given in Table 3 as $\bar{Y}$. Second, it could be calculated also as the mean of the $\log$ magnitude estimates at some level of background and TF square, when TF and reference field were under the same illuminance. These are given in Table 3 as $\bar{Y}_{m}$. Both sets were calculated from the values in Table 2 .

The values for $\bar{Y}$ and $\bar{Y}_{m}$, it will be noted, are very similar. That $\bar{Y}_{m}$, derived from a single illuminance, approximated $\bar{Y}$, which was derived by averaging the responses for seven illuminances, is another measure of the symmetry of the data over the approximately equal changes in illuminance. However, because it is conventional to use $\bar{Y}$ as the measure of 
the $y$-intercept, that practice will be followed here.

The GMs for $\bar{Y}$ in the last column of Table 3 indicate that on the average the white background gave the lowest value (1.93), the black background, the fighest value (2.03), and the gray background, an intermediate value (1.99). Moreover, these average differences were significant $F=8.02$, df $=2 / 22, p<.01$ ). It might seem, therefore, that on the average the white background had an inhibitory effect on the TF squares and shifted the brightness functions downward from the log modular value of 2.0 , whereas the black background had a disinhibitory effect and shifted the brightness functions upward.

Consider, however, the trends in $\overline{\mathrm{Y}}$ in Table 3 for the black and white backgrounds as TF squares were varied from black to white. For the black background the trend appears monotonically positive. For the white background it appears monotonically negative. In other words, it was the white TF squares, not the black or dark gray ones, that were inhibited by the white background and disinhibited by the black background. Consider, for example, the differences in $\bar{Y}$ for the black and white backgrounds at each level of TF square. These differences, subtracting $\bar{Y}$ for the black from $\bar{Y}$ for the white background in Table 3 , are: $+.06,-.03,-.08,-.12,-.14$, -.22 , and -.18 , respectively. Except for the value of -.22 , these points form a straight line $\left(\mathrm{r}^{2}=.991\right)$ when plotted against any set of log TF luminances (for example, in Table 2 the set from -.82 to $+.97)$. This line, with its slope of -.13 and its $y$-intercept (for the log TF luminances shifted to give a mean of zero) of -.08 , appears to contradict the literature on simultaneous contrast. To be in accord with that literature its slope should be positive, not negative. When the white background replaced the black background the darkest TF squares should have been more inhibited and the whitest TF squares less inhibited (Diamond, 1953; Heinemann, 1955; Hess \& Pretori, 1969; Torii \& Uemura, 1965).

The cross-over interaction was significant $(F=5.89, \mathrm{df}=12 / 132, \mathrm{P}<.01)$ and as a result of it there was no significant main effect of TF squares ( $F=1.82$, $\mathrm{df}=6 / 66, \mathrm{p}>.05)$.

The interaction has been described for $\bar{Y}_{S}$, which are the log brightness responses averaged for seven illuminances. Nevertheless, this fluctuation in $\bar{Y}$ with change in background also describes the fluctuation of $\bar{Y}_{e}$ with the same change in background, where $\bar{Y}_{\mathrm{e}}$ refers to the mean log magnitude estimates at some level of illuminance. It is to be understood, however, that these incremental (or decremental) effects must be taken in conjunction with other incremental effects at a particular level of illuminance: for example, the effect of a change in $\bar{b}$ for $a$ TF square on a black vs a white background. Even so, the interaction can clearly be seen in Table 2 for the seven levels of iluminance. The shifts are all positive. Now perform the same comparison for the last row of the table. The shifts are all large negatives. At all levels of illuminance. As an example, in the first row of Table 2, compare the change in response from the black to white background for the seven levels of illuminance. The shifts are all positive. Now perform the same comparison for the last row of the table. The shifts are all large negatives. At all levels of illuminance, therefore, the black TF square became brighter when the white replaced the black background, whereas the whitest TF square became considerably darker.

\section{GENERAL DISCUSSION}

\section{(1) The Failure to Find "-" Functions}

A number of changes in Jameson and Hurvich's (1961) experimental arrangements and procedures were described which, it was hoped, would increase the probability of observing "-" functions. That they were not observed might reflect on a number of other changes that have not been discussed. First, in Jameson and Hurvich's experiment Ss adjusted a small rectangular spot to match the TF square. Later, Ss were required to give magnitude estimates to a range of luminances of the matching spot. The match responses were then transformed to $\log$ magnitude estimates. Although the match response or middle step was eliminated in this experiment, there is no reason to assume that fact was the factor of difference.

Second, Jameson and Hurvich allowed their binocular monoptic Ss to look back and forth freely from TF to matching field. But Hess and Pretori (1969), who were presumed to have found "-" functions, also used a monoptic display, although with a fixation point and with monocular viewing. In the present experiment the presentation was dichoptic without fixation. That might have been a factor of difference, but we doubt it because the positive growth in brightness of the black TF square with increased illuminance seems to us to be selfevident. In other words, it can be observed readily with our displays under nonexperimental, free-inspection, monocular and binocular monoptic conditions of viewing.

Third, the task in the present experiment was explicitly to judge brightness. It was not clear from Jameson and Hurvich's (1961) use of the terms brightness and lightness if they made a distinction. If they did not and if their Ss, as a result, self-instructed themselves to make lightness instead of brightness judgments, perhaps that was a factor of difference. We doubt that is the case, however, and we base this belief on experimental evidence (Flock, 1969).

It seems to us that "-." functions observed by Jameson and Hurvich were probably consequent upon some marked asymmetries in their experimental procedures between preadaptation and TF luminances. Jameson and Hurvich presented their 15 experimental conditions (five TF squares $x$ three illuminances) in a random order and then replicated the experiment. The background for the adjustable spot of light was $1.78 \log \mathrm{mL}$, and subtended an angle of about $145 \mathrm{deg}$ at the eyes. Since S looked back and forth between the matching field and the TF, he was always light adapted to the level of $1.78 \mathrm{log} \mathrm{mL}$ when he examined the TF. At the lowest and middle illuminance, the black TF square was $-1.2610 \mathrm{~g} \mathrm{~mL}$ and $-.96 \log \mathrm{mL}$, respectively, and therefore was 3.04 and $2.79 \log \mathrm{mL}$ below the light adaptation of the eye. Were the black TF square to have been assimilated to the gray background under those conditions, then the judgment, purportedly of a detectable black TF square, was in fact of the assimilated square to background. At the highest illuminance, the black TF square was $1.93 \log \mathrm{mL}$ below the light adaptation of the eye. At that level, perhaps the black TF square was discriminable from the background and so would then be judged for what it was, a luminance region at some distance below the background luminance. That would vield a negative function.

This explanation is consistent with one other fluctuation in Jameson and Hurvich's data. When their dark-gray TF square was under the lowest illuminance, its luminance of $-.85 \log \mathrm{mL}$ was $2.63 \log \mathrm{mL}$ below the light adaptation of the eye. For that ratio also, perhaps the TF square assimilated with the background and yielded a high judgment. At the middle level of illuminance the ratio was $2.34 \log \mathrm{mL}$, which might have yielded a detectable square and therefore the lower brightness judgment that, in fact, occurred.

The explanation given here is also in accord with threshold values that can be extrapolated from some curves of Stevens and Stevens (1963, Fig. 6). With Jameson and Hurvich's (1961) preadaptation level equal to $87.8 \mathrm{~dB}$, that value gives an absolute threshold, reading from Stevens and Stevens's curves, of about $61.5 \mathrm{~dB}$. Hence, a stimulus that is $26.3 \mathrm{~dB}$ or $2.63 \mathrm{log} \mathrm{mL}$ below a preadaptation field of $1.78 \mathrm{~mL}$ will not be detectable. The critical 
limit of $2.63 \log \mathrm{mL}$ agrees very well with the values described above.

In the present experiment the preadaptation field was $1.64 \log \mathrm{fL}$, and the darkest region, $2.46 \log \mathrm{fL}$ below that value, was, perhaps, .17 $\log \mathrm{fL}$ above the absolute threshold. Perhaps it is the case, therefore, that negative functions can be generated simply by using TF luminances that are below the threshold specific to a preceding high-luminance preadaptation field. (That experiment is being planned.) ${ }^{5}$

Mention should be made here of some intuitive evidence cited by Jameson and Hurvich (1961, p. 175) in support of "-" functions. $A$ bottle of india ink and black telephone casings, we are told, become darker as illumination is increased. We do not know if that is the case. But it surely is the case that a bottle containing india ink and the black casings of telephones are both highly specular. For such surfaces the luminance distributions on the retina to which the retina is sensitive may be quite different as illumination is varied. Moreover, Jameson and Hurvich's (1964) model, tested here, assumed the homogeneity of the different interacting regions that it described. In an experiment, therefore, the different regions should be first approximations to Lambertian surfaces. The matte surfaces used in the present experiment were that. Whether or not Jameson and Hurvich's surfaces were first-approximation J ambertian. however, we do not know.

Finally, before leaving the matter of "-" functions attention should be drawn to the families of hypothetical curves published by Stevens (1961) and Bartleson and Breneman (1967) and to the data of Hess and Pretori (1969), the last having been cited by Jameson and Hurvich (1961). In the arrays of Stevens and of Bartleson and Breneman, negative brightness functions were shown. But in neither case were experiments and/or data described to corroborate the necessity for the curves.

By implication Hess and Pretori's (1969) data could be construed to be power curves with "+" and "-" exponents. (For a review of this, see Flock, 1970.) It may be, however, that Hess and Pretori were unsure of the reliability of some if not all of the implied "-" exponents. For one thing, they seemed to say so (Hess \& Pretori, 1969, p. 16). For a second, they replicated their experiment for the conditions implying " + " exponents, but not for the conditions implying "-." exponents. Whether or not they tried to replicate but couldn't is, of course, unknown.

(2) Theories and Empirics of Brightness Constancy

In this paper an experimental test was made of Jameson and Hurvich's theory of brightness constancy. The theory required the brightness functions to be power curves and, quintessentially, to have exponents restricted to the values of $.33,-.33$, ana 0 . The assumption of power curves was tenable. But there was no evidence that the exponents took values of $.33,-.33$, and 0 . On the basis of these data, therefore, the theory must be rejected. Nor was it possible to find a data configuration like that observed by Jameson and Hurvich (1961), although efforts were made to achieve that configuration.

The experimental data described in this paper would probably also fail to satisfy the theories of Wallach and Woodworth and Schlosberg. Wallach's theory requires brightness functions to have slopes of zero, which were not observed. Woodworth and Schlosberg's theory could perhaps handle slopes other than zero, but it would probably require the functions under the experimental conditions used here to be parallel, which was also not observed. Helson's theory might give the best fit to the data, were it possible, for the present conditions, to specify the adaptation levels when each TF square functioned as a focal region.

In other words, the data cited here may fit none of the prevailing theories. Nevertheless, each of those theories is defined with data. And much of the defining data conforms to the experimental paradigm of three luminance regions (focal, surround, and the surround of the surround) or of what might be called the classical experiment on simultaneous brightness contrast.

Four questions come to mind: First, in view of the precision associated with the classical experiment ${ }_{\text {}}$ on simultaneous contrast, why the discrepancy in their defining data? Second, is it desirable to tie the problem of brightness constancy so closely to the classical experiment on simultaneous contrast? As a problem brightness constancy refers to the fact that the achromatic color of a surface supposedly remains phenomenally invariant over changes of illumination and changes in the distance, shape, size, and orientation of a surface in a complex environment. On each occasion that brightness constancy is tied to the classical experiment, perhaps it would be desirable to compare the results to those elicited with more complex displays. (An experiment comparing the effects of these different arrangements is at present being carried out.) Third, can we continue to ignore the distinctions between brightness and whiteness? The classical experiment elicits a brightness response. Brightness constancy, misnamed, really refers to whiteness, not brightness. Fourth, can the matching technique really be justified in the contrast experiment? Consider the problem: $\mathbf{S}$ is often presented with a focal and surround luminance on one side and a focal luminance surrounded by darkness on a second side. In the former case the contrast conditions operationally define what is generally meant by achromatic color. In the latter case the absence of contrast conditions (darkness in the surround gives a CR of 0 ) operationally defines what is generally meant by brightness or by luminousness. The $S$ in these experiments is required to match what is preeminently "bright" with something that under some conditions (as when $\mathrm{CR}$ is somewhat below or above 1.0 ) preeminently has an achromatic quality and under other conditions (as when CR is substantially less than 1.0 ) preeminently lacks an achromatic quality and appears luminous or what is called "bright." There may be consistency between Ss with regard to such tasks, but what are the Ss doing?

\section{REFERENCES}

BARTLESON, C. J., \& BRENEMAN, E. J. Brightness perception in complex fields. Journal of the Optical Society of America, $1967,57,953-957$.

DIAMOND, A. L. Foveal simultaneous brightness contrast as a function of inducing-field luminance. Journal of Experimental Psychology, 1953, 45, 304-314.

FLOCK, H. R. Lightness changes in a complex field with changing illumination and background. Paper presented at the meeting of the Eastern Psychological Association, Philadelphia, April 1969.

FLOCK, H. R. Jameson and Hurvich's theory of brightness contrast. Perception \& Psychophysics, 1970, 8, 118-124.

GELB, A. Die "Farbenkonstanz" der Sehdinge. In A. Bethe, G. V. Bergmann, G. Embden, and A. Ellinger (Eds.) Handbuch der normalen und pathologischen Physiologies. Vol. 12, Part I. Berlin: Julius Springer, 1929. Po. 594-678.

HEINEMANN, E. Simultaneous brightness induction as a function of inducing- and test-field luminance. Journal of Experimental Psvchologv, 1955, 50, 89-96.

HELMHOLTZ, H. (Translated by J. C. P. Southall) Physiological optics. Rochester: Optical Society of America, 1925.

HELSON, $H$. Some factors and implications of color constancy. Journal of the Optical Society of America, 1943, 33, 555-567.

HELSON, $H$. Constancy. International encyclopedia of the social sciences. New York: Macmillan \& Free Press, 1968, 11. Pp. 544-546.

HESS, C., \& PRETORI, H. Empirical investigation into the lawfulness of simultaneous brightness contrast. Graefe's Archives of Ophthalmology, 1894, 40, 1-24. (Translated by H. R. Flock \& J. H. Tenny. Technical Report FPL-1, 1969, York University. This translation is available free of charge to interested investigators by writing to Department of Psychology, York University, Toronto, Ontario.)

JAMESON, D., \& HUR VICH, L. M. Complexities of perceived brightness. Science, 1961, 133, 174-179.

JAMESON, D., \& HURVICH, L. M. Theory of 
brightness and color contrast in human vision. Vision Research, 1964, 4, 135-154.

KATZ, D. The world of colour. (Translated by R. B. MacLeod) London: Kegan Paul, 1935.

KOFFKA, K. Principles of gestalt psychology. New York: Harcourt Brace, 1935.

STEVENS, J. C., \& STEVENS, S. S. Brightness function: Effects of adaptation. Journal of the Optical Society of America, 1963, 53, 375-385.

STEVENS, S. S. To honor Fechner and repeal his law. Science, $1961,133,80-86$.

TORII, S., \& UEMURA, Y. Effects of inducing luminance and area upon the apparent brightness of test field. Japanese Psychological Research, 1965, 7, 86-100.

WALLACH, H. Brightness constancy and the nature of achromatic colors. Joumal of Experimental Psychology, 1948, 38, 310-324. WOODWORTH, R. S. \& SCHLOSBERG, $H$. Experimental psychology. New York: Holt, 1954.

\section{NOTES}

1. A shortened version of this paper was presented to the 1968 meetings of the Eastern Psychological Association, in Washington, D.C. The experiment described below was carried out at York University. This research was supported by the National Research Council of Canada Grant No. APA-143.

2. Address: Department of Psychology, York University, Toron to, Canada.

3. The TF luminances were measured at their centers from the viewing position. The measurements for the background luminance refer to the background at the geometric center of the display. Adjacent to Square 6 in Table 2, the background luminances were $.12 \log \mathrm{fL}$ less than the values given. Adjacent to Squares 1 and 2 , they were $.06 \mathrm{log} \mathrm{fL}$ less.

4. $\bar{Y}$ fluctuated around the value of 2.0 for the gray background. Note that the log modular value of each $T F$ square in the reference field was 2.0 , the background of that field was gray, the changes in TF illuminance were approximately equal, and the brightness functions were approximately linear. Hence, the mean responses for TF squares on the gray background would fluctuate at or near a value of 2.0 , as they in fact did.

5. It should be noted that Stevens and Stevens's thresholds were for a short nash of light against darkness. In the experiments described here, the detection task was quite different. Moreover, the angular magnitude of the field of light adaptation in our experiment was only 5 deg; no fixation was held and no restriction on the duration of viewing was set. There would be no reason to expect, therefore, that Stevens and Stevens's threshold values would generalize to our experiment. Their values might have been relevant, however, to Jameson and Hurvich's experiment, in which the conditions may have been more similar.

(Accepted for Publication November 1, 1969.) 